\title{
Proteomic Analysis of Pathogenic Fungi Reveals Highly Expressed Conserved Cell Wall Proteins
}

\author{
Jackson Champer ${ }^{1}$, James I. Ito ${ }^{2}$, Karl V. Clemons ${ }^{3,4}$, David A. Stevens ${ }^{3,4}$ and \\ Markus Kalkum ${ }^{1, *}$
}

Received: 24 November 2015; Accepted: 5 January 2016; Published: 12 January 2016

Academic Editor: Luis V. Lopez-Llorca

1 Department of Molecular Immunology, Beckman Research Institute of City of Hope, Duarte, CA 91010, USA; jtchamper@yahoo.com

2 Division of Infectious Diseases, City of Hope National Medical Center, Duarte, CA 91010, USA; JIto@coh.org

3 California Institute for Medical Research, San Jose, CA 95128, USA; clemons@cimr.org (K.V.C.); stevens@stanford.edu (D.A.S.)

4 Division of Infectious Diseases and Geographic Medicine, Stanford University, Stanford, CA 94305, USA

* Correspondence: mkalkum@coh.org; Tel.: +1-626-301-8301; Fax: +1-626-301-8186

\begin{abstract}
We are presenting a quantitative proteomics tally of the most commonly expressed conserved fungal proteins of the cytosol, the cell wall, and the secretome. It was our goal to identify fungi-typical proteins that do not share significant homology with human proteins. Such fungal proteins are of interest to the development of vaccines or drug targets. Protein samples were derived from 13 fungal species, cultured in rich or in minimal media; these included clinical isolates of Aspergillus, Candida, Mucor, Cryptococcus, and Coccidioides species. Proteomes were analyzed by quantitative $\mathrm{MS}^{\mathrm{E}}$ (Mass Spectrometry-Elevated Collision Energy). Several thousand proteins were identified and quantified in total across all fractions and culture conditions. The 42 most abundant proteins identified in fungal cell walls or supernatants shared no to very little homology with human proteins. In contrast, all but five of the 50 most abundant cytosolic proteins had human homologs with sequence identity averaging 59\%. Proteomic comparisons of the secreted or surface localized fungal proteins highlighted conserved homologs of the Aspergillus fumigatus proteins 1,3- $\beta$-glucanosyltransferases (Bgt1, Gel1-4), Crf1, Ecm33, EglC, and others. The fact that Crf1 and Gel1 were previously shown to be promising vaccine candidates, underlines the value of the proteomics data presented here.
\end{abstract}

Keywords: proteomics; vaccine candidates; Aspergillus; Candida; fungal pathogens

\section{Introduction}

Pathogenic fungi, particularly Aspergillus fumigatus and Candida albicans, cause several thousand deaths per year among immunocompromised patients [1-9]. Coccidioides infection can occur in immunocompetent individuals [10]. Control and treatment of fungal infections is often challenging. Existing antifungal drugs are limited in effectiveness [11], and several species of fungi are becoming resistant to these treatments [12-15]. Thus, improved methods should be developed for the treatment and prevention of fungal infection.

Protein vaccines have been successful in several models of invasive fungal infection. For example, we have shown that vaccination with recombinant A. fumigatus Asp f3 (Pmp20) protected mice from aspergillosis following neutropenia or corticosteroid induced immunosuppression [16-19]. Additionally, vaccine formulations with Crf1 [20-22], Gel1 [21], and Pep2 [21] provided protection against aspergillosis in comparable experiments. Pmp1 from Coccidioides was an effective vaccine in a murine model of coccidioidomycosis [23], as were the proteins Pep1 [24] and Gel1 [25], Protection 
from candidemia has been conferred by immunization with recombinant Mdh1 [26], Sap2 [27], and Als3 [28-30], the last two have been investigated in clinical trials [31,32].

Several lines of evidence support the notion that developing a pan-fungal vaccine or at least a broad-spectrum vaccine that would protect against multiple fungal species may be feasible [33,34]. An ideal vaccine would protect against infection by multiple species of fungi by containing conserved epitopes that elicit both $\mathrm{T}$ cell and antibody responses. If protein based, such a vaccine candidate should be abundantly expressed as homologs by multiple species of fungi, preferably have cell wall localization, and be most dissimilar to any human protein. However, no large comparative proteomic studies have been published to date. Here, we report the quantitative proteomic analysis of 13 species of medically relevant fungi using a label-free $\mathrm{MS}^{\mathrm{E}}$ (Mass Spectrometry-Elevated Collision Energy) approach [35-39]. These results serve as a beginning step in our efforts toward the development of a pan-fungal vaccine.

\section{Materials and Methods}

\subsection{Fungal Strains}

All Aspergillus and Candida strains were isolated from patients at the City of Hope National Medical Center under the institutional review board (IRB)-approved protocol \#05024. These clinical isolates included A. fumigatus COH1 [16,19,40], A. fumigatus 685, A. flavus 654, A. terreus 638, A niger 663, A. nidulans 730, C. albicans 671, C. tropicalis 708, C. parapsilosis 719, and C. glabrata 612 (numbers are referring to our internal collection of isolates). Identification was performed by the clinical laboratory at City of Hope and validated in mass spectrometry proteomics experiments by comparing the number of hits obtained from proteomic databases. Additional fungal strains included Mucor circinelloides strain NRRL 3631 (The U.S. Department of Agriculture, Agricultural Research Service Culture Collection), Cryptococcus neoformans var. grubii H99 (clinical isolate, Fungal Genetics Stock Center), C. posadasii strain Silveira (ATCC 28868) [41], and S. cerevisiae strain W303 (gift from Michael P. Rout, Rockefeller University, NY, USA). S. cerevisiae ("baker's yeast") was included because of the protective effect a heat-killed yeast antifungal vaccine has demonstrated previously [33,42-44], and because of growing numbers of reports of invasive Saccharomyces infections [45].

\subsection{Culture Conditions}

Both minimal and rich media were used in parallel for the culturing fungal organisms at $37^{\circ} \mathrm{C}$. These were the Czapek Dox (CD) minimal medium and the Potato Dextrose (CD) rich medium (both from Difco, Detroit, MI, USA). Although PD medium is typically used for the culturing of filamentous fungi, we used the same medium for yeasts to facilitate better proteomics comparisons between the genera. The inoculum size was $10^{7}$ spores or yeast cells for the molds Aspergillus and Mucor, or the yeasts Candida, Cryptococcus, and Saccharomyces, respectively. Cultures were harvested in the late exponential growth phase, 16-24 h after inoculation for PD medium and 2-5 days for CD medium, depending on the species. For $C$. albicans, it was necessary to supplement $C D$ medium with $1 \mathrm{mg} / \mathrm{mL}$ casamino acids (Sigma Chemical Co., St. Louis, MO, USA) to ensure optimal growth (designated as $\mathrm{CD}+$ medium). C. posadasii could not be cultured well in the media listed above and was therefore grown in a rich broth of $2 \%$ glucose and $1 \%$ yeast extract for 5 days at ambient temperature on a gyratory shaker at $150 \mathrm{rpm}$. Culturing and sample preparation of the hyphal form of $C$. posadasii was done in a BSL3 facility at the California Institute for Medical Research.

\subsection{Sample Preparation}

To prepare cell extracts (CE), yeasts were pelleted by centrifugation while hyphae of molds, except C. posadasii, were collected on filter paper and then partially dried using paper towels. Such yeast pellets and hyphal mats ( $10 \mathrm{~g}$, wet weight) were frozen under liquid nitrogen, and $50 \mu \mathrm{L}$ of $100 \mathrm{mM}$ PMSF and $50 \mu \mathrm{L}$ of mammalian protease inhibitor cocktail (Sigma, St. Louis, MO, USA) was added. 
To disrupt cells, fungi were then ground in frozen state with a MM301 ball mill (Retsch, Haan, Germany) essentially as previously reported [46]. Briefly, frozen fungus samples were ground for three cycles at $30 \mathrm{~Hz}$ for $3 \mathrm{~min}$ while the temperature was maintained by submerging the stainless steel grinding jars into liquid nitrogen between cycles. Subsequently, the ground samples were suspended in Milli-Q purified deionized water (Millipore, Billerica, MA, USA) and sonicated with a Sonicator 3000 (Misonix, Farmingdale, NY, USA) using $60 \times 0.75 \mathrm{~s}$ pulses at power setting 5 with 0.25 -s intervals between pulses. The completeness of cell disruption was verified by microscopy. C. posadasii $\mathrm{CE}$ was prepared by vortex mixing of hyphae with $0.45 \mathrm{~mm}$ glass beads in $15 \mathrm{~s}$ cycles alternating with chilling in an ice bath. Homogenates were clarified by centrifugation and supernatants filtered through PVDF membranes with $0.22 \mu \mathrm{m}$ pores (Millipore, Billerica, MA, USA). Culture filtrate (CF) was obtained by filtering spent fungal growth medium through membrane filters with $0.22 \mu \mathrm{m}$ pores, addition of $10 \mu \mathrm{L}$ fungal protease inhibitor cocktail (Sigma), and concentration by partial lyophilization to approximately $1 \mathrm{~mL}$ volume, followed by addition of trichloroacetic acid (TCA) to a final concentration of $200 \mathrm{mg} / \mathrm{mL}$ on ice. Samples were centrifuged at $4{ }^{\circ} \mathrm{C}$, and the protein precipitates were retained. Cell wall (CW) extract was obtained by digestion of live fungal organisms for 8 hours at $30^{\circ} \mathrm{C}$ in a digestion cocktail containing $1 \mathrm{~mL}$ with addition $10 \mu \mathrm{L}$ fungal protease inhibitor cocktail (Sigma), $200 \mathrm{U} / \mathrm{mL}$ lyticase (Sigma), and $20 \mathrm{U} / \mathrm{mL}$ chitinase (Sigma), followed by centrifugation and filtration of the supernatant through a Millex PVDF filter with $0.22 \mu \mathrm{m}$ pores (Millipore, Billerica, MA, USA).

\subsection{Firefly Luciferase Quantification Standard for $M S^{E}$}

Recombinant Firefly Luciferase (FFL) was used to explore the dynamic range of MS ${ }^{\mathrm{E}}$ quantification and as a standard. FFL cDNA was copied from the pGAL-FFL[SEL] plasmid (Addgene plasmid \#1102 [47]), cloned into a NcoI/ XhoI restricted pET28 vector (Novagen, EMD Biosciences, Madison, WI, USA) and expressed in BL21 Escherichia coli. The recombinant protein was purified via chromatography through a nickel nitrilotriacetic acid column and by gel filtration. Purity and identity was verified by SDS gel electrophoresis and mass spectrometry. FFL with $>\sim 98 \%$ purity was added to each sample at $500 \mathrm{fmol}$ per $\mu \mathrm{g}$ protein before trichloroacetic acid precipitation as a quantification standard.

\subsection{Mass Spectrometry}

Proteins from CE and CW fractions were precipitated in $200 \mathrm{mg} / \mathrm{mL}$ TCA as described above. Approximately $12.5 \mu \mathrm{g}$ of protein from each sample was suspended in a buffer containing $50 \%$ trifluoroethanol and $100 \mathrm{mM}$ ammonium bicarbonate buffer at $\mathrm{pH}$ 8. Samples were reduced with tris(2-carboxyethyl)phosphine and alkylated with iodoacetamide. Additional ammonium bicarbonate buffer was added to reduce the trifluoroethanol concentration to $5 \%$, and samples digested for $16 \mathrm{~h}$ at $\mathrm{pH} 8$ with $6.25 \mu \mathrm{g} / \mathrm{mL}$ sequencing grade modified trypsin (Promega, Madison, WI, USA). MS ${ }^{\mathrm{E}}$ mass spectrometric analysis was conducted using a SYNAPT G2 HD quadrupole time-of-flight (Q-TOF) mass spectrometer equipped with ion mobility separation unit and a nano Acquity 2D UHPLC system with a tile based Trizaic ion source (Waters, Milford, MA, USA). The mass range was 50-2000 Da, ion mobility separation (IMS) wave velocity was $650 \mathrm{~m} / \mathrm{s}$, and IMS wave height was $40 \mathrm{~V}$. Solvents were $0.1 \%$ formic acid for buffer A and $0.1 \%$ formic acid in acetonitrile for buffer B. UHPLC chromatography was performed with a Trizaic for proteomics nanoTile containing $1.8 \mu \mathrm{m}$ C18 particles in a $85 \mu \mathrm{m}$ internal diameter $\times 100 \mathrm{~mm}$ column, by applying a linear solvent gradient over $50 \mathrm{~min}$ of $3 \%$ buffer $\mathrm{B}$ at the start, transitioning to $35 \%$ by minute $30,50 \%$ by minute $34,90 \%$ by minute 35 , holding $90 \%$ through minute 38 , transitioning to $3 \%$ buffer B by minute 43 , and holding at $3 \%$ through minute 50 . Collision energy was ramped automatically from $15-40 \mathrm{eV}$. Culturing, fractionation, and protein extraction were gradually improved over several trials for each fungus. The samples with the highest protein recovery and sequence coverages were then chosen for triplicate $\mathrm{MS}^{\mathrm{E}}$ analyses on the mass spectrometer for protein quantification. 


\subsection{Protein Analysis}

Data were analyzed using IdentityE (version 2.135.2.0, Waters, Milford, MA, USA) with default parameters in Protein Lynx Global Server (PLGS) (version 3.0.2, Waters, Milford, MA, USA). Search parameters included trypsin-derived peptides with up to one missed cleavage. Fixed modifications included carbamidomethyl addition to cysteine, and variable modifications included oxidized methionine. Mass tolerance was 0.025 Da for low energy ions and $0.01 \mathrm{Da}$ for high energy ions. Protein databases searched included NCBI June 2014 versions of A. fumigatus Af293, A. flavus NRRL3357, A. terreus NIH2624, A. niger CBS 513.88, A. nidulans FGSC A4, C. albicans SC5314, C. tropicalis MYA-3404, C. glabrata CBS 138, C. parapsilosis CDC317, C. posadasii strain Silveira, C. neoformans var. grubii H99, and S. cerevisiae S288c. For identical proteins within each database, accession numbers were used with Swiss Protein as first priority, RefSeq as second priority, and others as third priority. Additionally, version 2.0 of Mucor circinelloides from the Joint Genome Institute was used. Common contaminant proteins were added to each database (Supplemental FASTA File 1). Scaffold 4.4.1 (Proteome Software, Portland, OR, USA) was used for quantification of proteins using a maximum false discovery rate of $5 \%$ as calculated by hits on the corresponding sequence-reversed database, with protein and peptide confidence levels adjusted to provide the maximum number of hits for the false discovery rate. $\mathrm{MS}^{\mathrm{E}}$ protein quantifications were based on the average peak intensity of the top three peptides from each protein (or two for proteins with only two peptides available) and were normalized to femtogram of protein detected per microgram of total protein injected for each sample LC/MS ${ }^{\mathrm{E}}$ analysis. For cases of peptides matching to multiple protein families, Scaffold assigned individual proteins using unique peptides and parsimony rules. Protein localization was predicted with the WoLF PSORT tool [48]. Matching of homologous proteins between fungal species was facilitated with a set of python scripts that included the following libraries: biopython, numpy, and matplotlib. The first script generated BLAST [49] homology data for each A. fumigatus protein in each of the fungal species examined by executing NCBI's standalone BLASTP software version 2.2.30 with the default BLOSUM62 matrix, an expectation value of $e<0.05$, a gap open value of 11 , and a gap extension value of 1 . With a second script, each $\mathrm{MS}^{\mathrm{E}}$ quantified fungal protein homolog was identified in the BLASTP XML output using an expectation value of $e<10^{-10}$ and $>30 \%$ sequence identity defined as the ratio of the number of identical residues over the length of the query sequence. Homologies to human proteins (Human RefSeq, NCBI Reference Sequence Database) were recorded for BLASTP expectation values of $e<10^{-20}$, due to the larger database size, and with $>20 \%$ sequence identity. Finally, a third python script was used to generate heatmaps that displayed the amount of the closest quantified fungal protein homolog by color coding and its numerical value for percent sequence identity with the corresponding A. fumigatus protein. We used the GI (GenInfo Identifier) accession numbers to match all fungal protein homologs except for Mucor circinelloides. The latter was performed using the IGI accession numbers from the Joint Genome Institute database.

\section{Results}

\section{1. $M S^{E}$ Label-Free Protein Quantification}

We assessed the dynamic range and linearity of the $\mathrm{MS}^{\mathrm{E}}$ instrument response with a series of $A$. fumigatus CE samples that contained varying concentrations of spiked-in recombinant FFL. The instrument response was approximately linear at lower FFL concentrations from 135 to approximately $1400 \mathrm{fmol}$ FFL per microgram of total protein (Figure S1), which corresponds to the concentration range in which nearly all of the fractionated fungal proteins were detected. For recombinant FFL, a saturation effect was observed outside the relevant range, at FFL concentrations $>1400 \mathrm{fmol} / \mu \mathrm{g}$ total protein (Figure S1). 


\subsection{Mass Spectrometry of Fungal Fractions}

The workflow for the fractionation of fungal organisms to obtain proteins from whole cell extract (CE), culture filtrate (CF), and cell walls (CW) is shown in Figure 1. Proteins were identified and quantified separately for minimal and rich medium culture conditions. Detailed protein quantification results are listed in Tables S1-S18. These include data from two clinical isolates of Aspergillus fumigatus AFCOH1 and \#685, Aspergillus flavus, Aspergillus terreus, Aspergillus niger, Aspergillus nidulans, Candida albicans, Candida tropicalis, Candida parapsilosis, Candida glabrata, Cryptococcus neoformans var. grubii, Mucor circinelloides, and Saccharomyces cerevisiae grown in PD medium, A. fumigatus, A. flavus, A. terreus, and $C$. albicans grown in $\mathrm{CD}$ medium, and in Coccidioides posadasii glucose yeast extract.

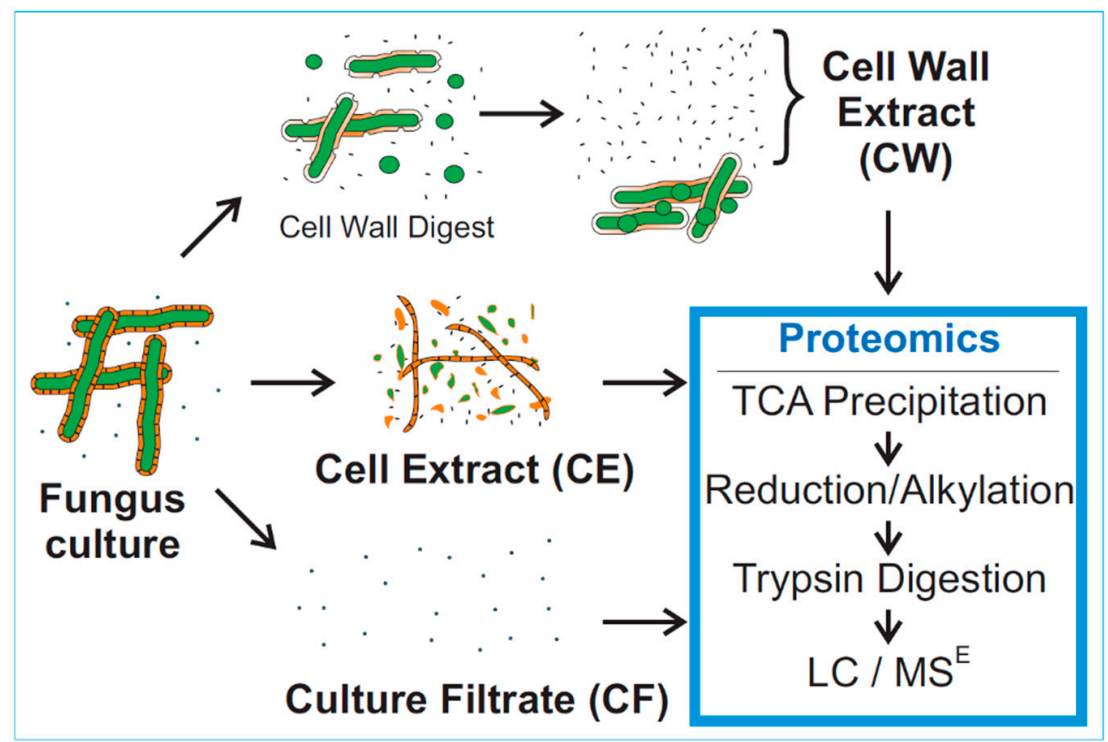

Figure 1. Workflow for generation of fungal protein fractions and processing for mass spectrometric analysis.

In total, several thousand unique proteins were identified and quantified by $\mathrm{MS}^{\mathrm{E}}$ across all fractions (Tables S1-S18), ranging from 167 proteins for A. flavus cultured in CD medium to 707 for A. fumigatus grown in PD medium (Figure 2). Proteins (363-664) were identified in CE fractions from each species of fungus grown in PD medium, and 132-320 proteins were identified in CE fractions from each species of fungus grown in CD medium. CF fractions contained 15-131 identified proteins and CW fractions contained 17-194 identified proteins. Most proteins found in CD fractions were also found in PD fractions from the same species.

WoLF PSORT [48] predicted Surface and Secreted Localization (SSL) for proteins in the CF and CW fractions (Table 1). SSL proteins had either predicted extracellular (including cell wall and secreted) or membrane localization. The CF fractions contained, in total, $65 \%$ identified proteins possessing predicted SSL, with most individual fractions having higher levels of predicted SSL proteins. However, some $\mathrm{CF}$ fractions suffered more heavily from intracellular protein contamination, particularly A. nidulans with $43 \%$ SSL, C. albicans grown in CD+ media with $42 \%$ SSL, C. parapsilosis with $40 \%$ SSL, and C. posadasii with 34\% SSL. The level of SSL in CW fractions was more varied, ranging from $27 \%$ in C. parapsilosis to $88 \%$ in A. niger, averaging $43 \%$ for proteins identified in all fungal species. 

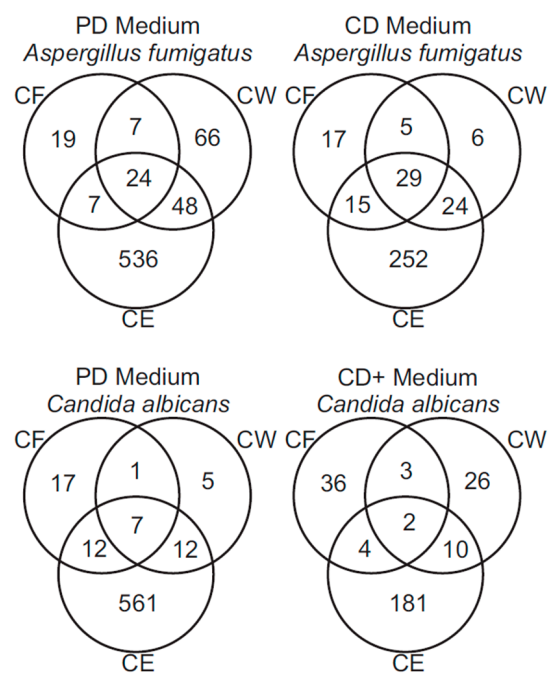

Figure 2. Number of proteins quantified in A. fumigatus and C. albicans fungal fractions. PD-Potato Dextrose Medium; CD—Czapek Dox Medium (+-with casamino acid supplementation); CE-Cell Extract Fraction; CF-Culture Filtrate Fraction; CW-Cell Wall Fraction. Protein numbers in overlapping sections of the Venn diagrams are of those shared by multiple fractions.

Table 1. Number of proteins quantified in each fungal fraction *.

\begin{tabular}{ccccccc}
\hline Species & Growth Medium & CE & CF & \%SSL & CW & $\%$ SSL \\
\hline Aspergillus flavus & PD & 508 & 25 & $80 \%$ & 86 & $38 \%$ \\
Aspergillus flavus & CD & 132 & 41 & $76 \%$ & 36 & $72 \%$ \\
Aspergillus fumigatus & PD & 615 & 57 & $70 \%$ & 145 & $38 \%$ \\
Aspergillus fumigatus 685 & PD & 510 & 62 & $95 \%$ & 194 & $33 \%$ \\
Aspergillus fumigatus & CD & 320 & 66 & $77 \%$ & 64 & $70 \%$ \\
Aspergillus nidulans & PD & 450 & 68 & $43 \%$ & 46 & $61 \%$ \\
Aspergillus niger & PD & 511 & 35 & $97 \%$ & 17 & $88 \%$ \\
Aspergillus terreus & PD & 580 & 25 & $96 \%$ & 84 & $50 \%$ \\
Aspergillus terreus & CD & 204 & 27 & $56 \%$ & 45 & $64 \%$ \\
Candida albicans & PD & 592 & 38 & $61 \%$ & 25 & $60 \%$ \\
Candida albicans & CD+ & 197 & 45 & $42 \%$ & 41 & $37 \%$ \\
Candida glabrata & PD & 363 & 33 & $91 \%$ & 57 & $33 \%$ \\
Candida parapsilosis & PD & 664 & 48 & $40 \%$ & 78 & $27 \%$ \\
Candida tropicalis & PD & 375 & 24 & $63 \%$ & 51 & $41 \%$ \\
Coccidioides posadasii & PD & 403 & 131 & $34 \%$ & 53 & $28 \%$ \\
Cryptococcus neoformans & PD & 609 & 15 & $80 \%$ & 30 & $40 \%$ \\
Mucor circinelloides & PD & 419 & 25 & $88 \%$ & 40 & $53 \%$ \\
Saccharomyces cerevisiae & PD & 481 & 16 & $94 \%$ & 46 & $28 \%$ \\
\hline
\end{tabular}

* PD-Potato Dextrose Medium; CD-Czapek Dox Medium (+-with casamino acid supplementation); CE-Cell Extract Fraction; CF-Culture Filtrate Fraction; CW-Cell Wall Fraction; SSL-Surface or Secreted Localization.

\subsection{Analysis of A. fumigatus and C. albicans Proteins}

Proteins from the major opportunistic pathogens A. fumigatus and C. albicans were assessed for fraction overlap. In total, 707 identified proteins were quantified in fractions from A. fumigatus grown in PD medium, 348 in fractions from A. fumigatus grown in CD medium, 615 proteins in fractions from C. albicans grown in PD medium, and 262 in fractions from C. albicans grown in CD+ medium (Figure 2). CF and CW fractions usually had considerable overlap between identified proteins in A. fumigatus, with less overlap in C. albicans, particularly when grown in CD+ medium. However, each fraction also had significant numbers of proteins not found in other fractions, several of which were abundant. 


\subsection{Interspecies Protein Comparisons}

To determine the proteins that are conserved between the different fungal species, the proteomics results for each fungal fraction and culture condition were compared to each other. To avoid ambiguities, interspecies comparisons were based on the protein sequence of each identified protein, and not on protein names or accession numbers. NCBI's BLASTP revealed many A. fumigatus and C. albicans homologs of abundantly expressed proteins in CE fractions and SSL proteins in CF and CW fractions (Tables S1-S18). These homologs were compared to proteins identified in A. fumigatus. Within these Supplemental Tables, the percent sequence identity is given.

Abundantly expressed $A$. fumigatus proteins usually had high degrees of homology with other Aspergillus species. For A. flavus, A. terreus, A. niger, and A. nidulans, homologies to A. fumigatus proteins ranged from $84 \%-87 \%$ for CE and $53 \%-64 \%$ SSL proteins (Table 2 ). Homology levels were nearly as high when comparing A. fumigatus and C. posadasii proteins, averaging $79 \%$ for CE and $49 \%$ for SSL proteins. A. fumigatus protein homology levels with other species including $M$. circinelloides, Candida species, C. neoformans var. grubii, and S. cerevisiae, were approximately $10 \%-25 \%$ lower than for the Aspergilli and C. posadasii (Table 2).

C. albicans proteins possessed high degrees of homology to proteins from C. tropicalis and C. parapsilosis, moderate homology to C. glabrata and S. cerevisiae, and lower levels of homology with other species (Table 3).

Considering all of the interspecies protein homology comparisons observed, it became clear that SSL proteins had lower levels of interspecies similarity than the intracellular proteins. However, SSL protein homologies were still substantial with $33 \%-64 \%$ sequence identity.

The 50 proteins identified as most abundant in CE fractions in all species analyzed are displayed in a heat map using color coding to visualize protein amounts and overlaid numbers to indicate the level of sequence identity respective to the homologous A. fumigatus protein (Figure 3). Forty-five of these fungal proteins had significant homology $(>20 \%)$ to human proteins with an average fungus-to-human sequence identity of $59 \%$. One protein, A. fumigatus ubiquitin had $100 \%$ sequence identity to human ubiquitin and slightly less homology to other fungal ubiquitins. The vaccine candidate Pmp20 (Asp f3) had highly expressed homologs in all species analyzed except $C$. neoformans var. grubii and it also had only $33 \%$ identity to its human homolog. The 42 A. fumigatus SSL proteins with the greatest number of highly expressed homologs among the species analyzed are displayed in a similar heat map in Figure 4. Of the 42 SSL proteins, only 8 had some homology ( $>20 \%)$ to human proteins. Those were Sed2, Alp2, two carboxypeptidase S1 proteins, catalase B, Pep1, CpdS, and a mannosidase. However, the latter averaged only $26 \%$ sequence identity when comparing the respective $A$. fumigatus protein to its closest human homolog. 
Table 2. Homology comparisons for the 50 most abundant CE proteins and all SSL proteins of Aspergillus fumigatus *

\begin{tabular}{|c|c|c|c|c|c|c|c|c|c|c|c|c|c|c|c|}
\hline Fraction & 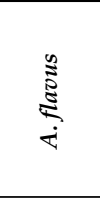 & $\overbrace{i}^{0}$ & 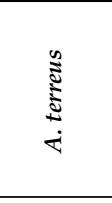 & 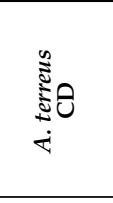 & 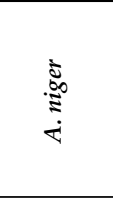 & 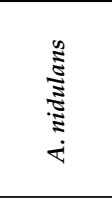 & 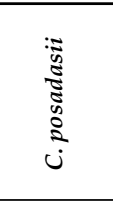 & 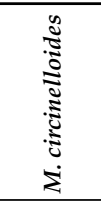 & 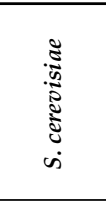 & 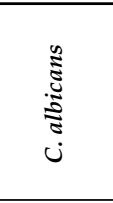 & 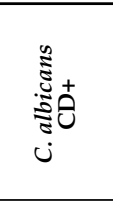 & 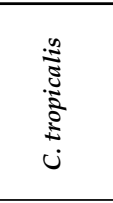 & 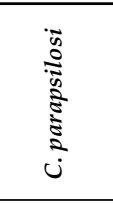 & 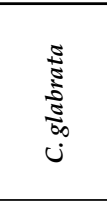 & 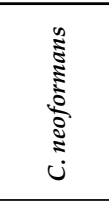 \\
\hline \# Proteins, CE & 47 & 40 & 50 & 47 & 49 & 50 & 46 & 46 & 48 & 48 & 47 & 46 & 48 & 46 & 48 \\
\hline $\begin{array}{l}\text { Average \% Identity } \\
\text { \# Proteins, CF }\end{array}$ & $85 \pm 14$ & $87 \pm 10$ & $85 \pm 12$ & $84 \pm 12$ & $85 \pm 15$ & $84 \pm 13$ & $79 \pm 13$ & $62 \pm 12$ & $64 \pm \frac{ \pm}{7}$ & $66 \pm 12$ & $65 \pm 12$ & $64 \pm 13$ & $66 \pm \frac{13}{7}$ & $65 \pm 13$ & $63 \pm 12$ \\
\hline $\begin{array}{c}\text { Average \% Identity } \\
\text { \# Proteins, CW }\end{array}$ & $56 \underset{25}{ \pm} 19$ & $53 \pm \frac{17}{23}$ & $60 \pm \frac{15}{34}$ & $60 \pm \frac{17}{25}$ & $56 \pm \frac{14}{17}$ & $57 \pm 12$ & $\frac{49 \pm 11}{13}$ & $33 \pm 3$ & $42 \pm 5$ & $42 \pm 5$ & $39 \pm 0$ & $40 \pm 6$ & $\begin{array}{c}37 \pm 7 \\
9\end{array}$ & $\frac{42 \pm 6}{12}$ & $31 \pm 0$ \\
\hline Average \% Identity & $59 \pm 17$ & $62 \pm 16$ & $61 \pm 16$ & $64 \pm 15$ & $53 \pm 16$ & $59 \pm 14$ & $50 \pm 12$ & $33 \pm 3$ & $42 \pm 6$ & $41 \pm 6$ & $41 \pm 7$ & $39 \pm 8$ & $39 \pm 7$ & $41 \pm 5$ & $31 \pm 0$ \\
\hline
\end{tabular}

* \#-number of; PD—Potato Dextrose Medium; CD—Czapek Dox Medium (+—with casamino acid supplementation); CE—Cell Extract Fraction; CF-Culture Filtrate Fraction; CW—Cell Wall Fraction. \pm indicates standard deviation.

Table 3. Homology comparisons for the 100 most abundant CE proteins and all SSL proteins of Candida albicans *

\begin{tabular}{|c|c|c|c|c|c|c|c|c|c|c|c|c|c|c|c|c|}
\hline Fraction & 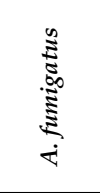 & 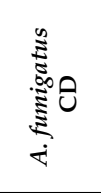 & 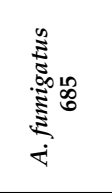 & 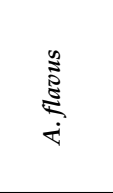 & $\sum_{i}^{\stackrel{n}{\tilde{E}}}$ & & 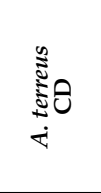 & 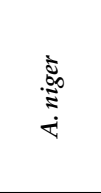 & 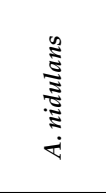 & 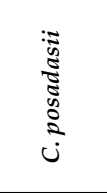 & 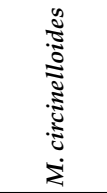 & 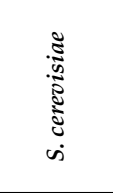 & 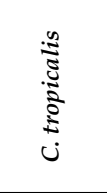 & 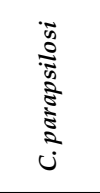 & 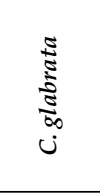 & 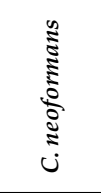 \\
\hline \# Proteins, CE & 88 & 74 & 95 & 93 & 75 & 97 & 91 & 91 & 95 & 83 & 93 & 96 & 97 & 98 & 99 & 96 \\
\hline $\begin{array}{l}\text { Average \% Identity } \\
\text { \# Proteins, CF }\end{array}$ & $66 \pm \frac{11}{5}$ & $65 \pm \frac{13}{5}$ & $66 \pm \frac{12}{5}$ & $66 \pm 13$ & $66 \pm 14$ & $65 \pm 13$ & $64 \pm \frac{14}{2}$ & $67 \pm 11$ & $65 \pm 13$ & $65 \frac{ \pm}{7} 13$ & $63 \pm 13$ & $74 \frac{ \pm}{7} 12$ & $90 \pm 10$ & $87 \underset{14}{ \pm} 10$ & $74 \underset{18}{ \pm} 12$ & $63 \pm 12$ \\
\hline Average $\%$ Identity & $41 \pm 5$ & $41 \pm 5$ & $41 \pm 5$ & $40 \pm 4$ & $40 \pm 5$ & $41 \pm 6$ & $42 \pm 2$ & $39 \pm 5$ & $37 \pm 6$ & $41 \pm 9$ & $32 \pm 0$ & $50 \pm 7$ & $56 \pm 16$ & $54 \pm 16$ & $47 \pm 10$ & $0 \pm 0$ \\
\hline \# Proteins, CW & 10 & 7 & 9 & 8 & 7 & 7 & 6 & 4 & $\overline{6}$ & 6 & 1 & $1 \overline{1}$ & $\overline{15}$ & $\overline{16}$ & 13 & 0 \\
\hline Average \% Identity & $38 \pm 5$ & $40 \pm 5$ & $39 \pm 5$ & $40 \pm 5$ & $40 \pm 6$ & $39 \pm 5$ & $37 \pm 4$ & $39 \pm 5$ & $41 \pm 6$ & $43 \pm 9$ & $32 \pm 0$ & $46 \pm 8$ & $60 \pm 17$ & $55 \pm 16$ & $44 \pm 10$ & $0 \pm 0$ \\
\hline
\end{tabular}

*\#-number of; PD—Potato Dextrose Medium; CD—Czapek Dox Medium; CE-Cell Extract Fraction; CF-Culture Filtrate Fraction; CW—Cell Wall Fraction. \pm indicates

standard deviation. 
fmol / $\mu$ g total CE protein

\begin{tabular}{cccccccc}
1,400 & 1,200 & 1,000 & 800 & 600 & 400 & 200 \\
$\mid$ & $\mid$ & $\mid$ & $\mid$ & $\mid$ & $\mid$ \\
\multicolumn{1}{c}{ Aspergillus fumigatus } \\
Quantified Protein - Accession (GI\#)
\end{tabular}

Fungus (Medium)

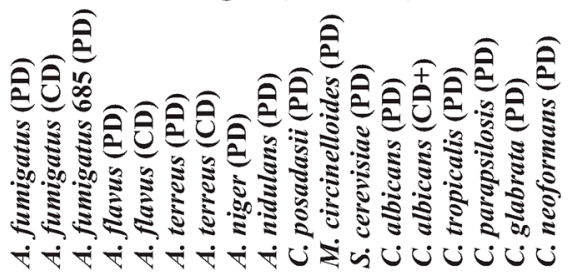

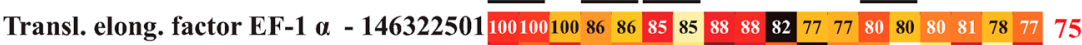

Glycerald. 3-phos. dehydrog. GpdA - 7098527810010010084 84 $81 \quad 81 \quad 8783 \quad 77 \quad 73 \quad 64 \quad 66 \quad 66 \quad 6464 \quad 637267$

Enolase Allergen Asp f 22 - 8328804610010010094 $94 \quad 979796 \quad 9490 \quad 68 \quad 72 \quad 75 \quad 75 \quad 76 \quad 7872 \quad 62 \quad 63$

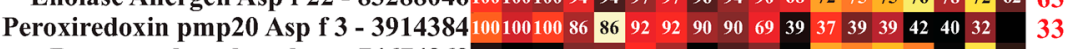

$\begin{array}{llllllllllllllllll}\text { Pyruvate decarboxylase - 74674363100 } & 100 & 83 & 83 & 84 & 84 & 84 & 84 & 75 & 42 & 46 & 48 & 48 & 46 & 46 & 48 & 46 & \text { no }\end{array}$

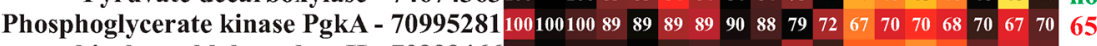

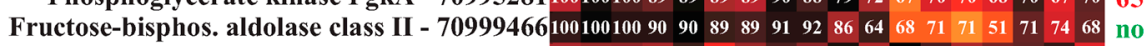

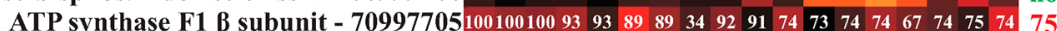

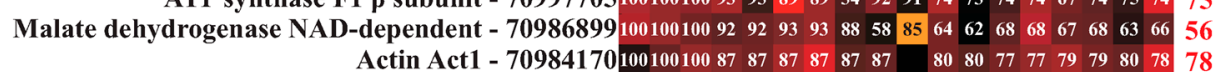

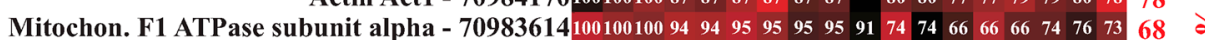

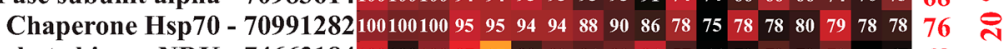

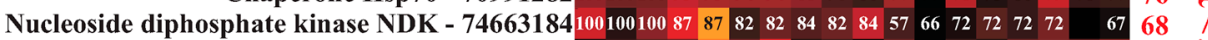
Histone H2B - 7467381210010010099 $999999999994 \quad 647476 \quad 76767474 \quad 6064:=$

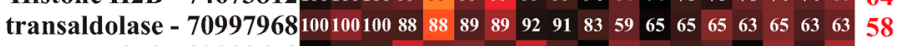

Heat shock protein 90 Allergen Asp f 12 - 8330365810010010092 $929494 \quad 9192897076 \quad 767674 \quad 757570 \quad 66$ Histone H2A - 90101335100100100100100 $98 \quad 98 \quad 10098 \quad 8183 \quad 7784 \quad 7580 \quad 8275 \quad 75 \quad 79$

Transl. elong. factor EF-2 subunit - 71002010100100100 $848481 \quad 8192 \quad 90 \quad 88747978 \quad 78778076 \quad 75 \quad 69$

Plasma membrane H+-ATPase Pma1 - 71000305100100100 80 80 $90 \quad 90889047 \quad 46 \quad 4646464646 \quad 31$

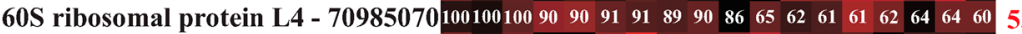
peptidyl-Pro cis-trans isomerase/cyclophilin - 71000343100100100 63 $66666 \begin{array}{llllllllllll}70 & 73 & 74 & 71 & 74 & 74 & 64 & 75 & 69 & 76 & 69\end{array}$

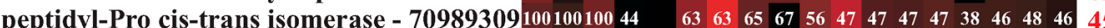
6-phosphogluconate dehydrog. Gnd1 - 70991695100100100 $898984 \quad 8490 \quad 86 \quad 82 \quad 687573 \quad 73 \quad 72 \quad 7272 \quad 6966$

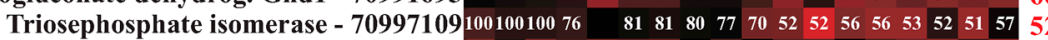

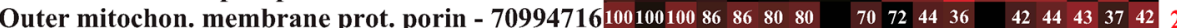
glucose-6-phosphate isomerase - 71001262100100100 $92 \quad 92 \quad 92 \quad 92 \quad 93 \quad 91 \quad 86 \quad 62 \quad 72 \quad 70 \quad 70 \quad 6970 \quad 7157 \quad 56$ euk. translat. elong. factor 1 Eef1- $\beta$ - 146322600100100100 $\quad \begin{array}{lllllllllllll}87 & 87 & 84 & 81 & 70 & 43 & 50 & 50 & 56 & 52 & 54 & 54\end{array}$ Hsp70 chaperone (HscA) - 70983346100100100 97 $58975898585864747777 \quad 77787466$

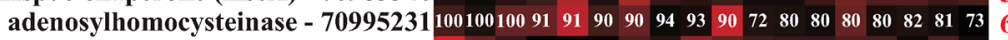
thioredoxin TrxA - 70997545100100100 $\quad 60 \quad 6058 \quad 6252 \quad 44 \quad 41 \quad 41 \quad 41 \quad 38 \quad 37 \quad 40 \quad 36$ pyruvate kinase - $70991575100 \quad 10092 \quad 92 \quad 92 \quad 93 \quad 93 \quad 84 \quad 53 \quad 64 \quad 6868 \quad 6768 \quad 6463 \quad 54$

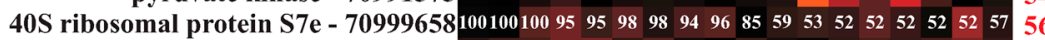
cobalamin-indept. Met synthase MetH/D - 7099462610010010091 $919090 \quad 9092 \quad 8653 \quad 62 \quad 63 \quad 63 \quad 63 \quad 64 \quad 62 \quad 56 \quad n$

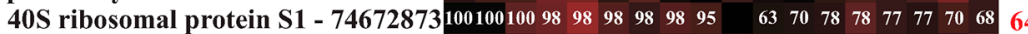
14-3-3 family protein ArtA - 70989229100100100 $87 \quad 87979796 \quad 92 \quad 8272 \quad 77 \quad 76 \quad 7674 \quad 76 \quad 7478 \quad 72$

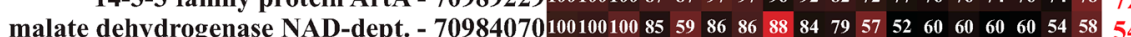
Peptidyl-Pro cis-trans isomerase B PPIase B - 74671259100 $4810052 \quad 4444 \quad 897972 \quad 4851565144515362$ 61

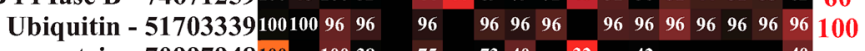

\begin{tabular}{ll|l|l|l|l|l|l|l|l} 
CipC-like antibiotic response protein - 70997948100 & 10038 & 75 & 73 & 40 & 32 & 42 & 40 & no
\end{tabular} SO dismutase [Mn] mito. Allergen Asp f 6 - 83305645100100100 $656563 \quad 6348 \quad 6451495049494948 \quad 5149$

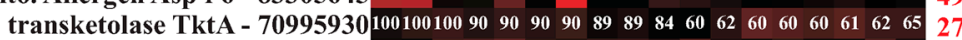
60S ribosomal protein L5 - 70995808100100100 $81 \quad 8182 \quad 82 \quad 80 \quad 83 \quad 76 \quad 54 \quad 65 \quad 64 \quad 64 \quad 63 \quad 63 \quad 65 \quad 56 \quad 47$ citrate synthase (Cit1) - 7098482810010010094 $94 \quad 9595 \quad 96 \quad 93 \quad 93 \quad 72 \quad 67 \quad 63 \quad 63 \quad 7068 \quad 64 \quad 64 \quad 61$

Glu/Leu/Phe/Val dehydrogenase - 7099477410010010091 $91 \quad 88 \quad 88 \quad 86 \quad 76 \quad 66 \quad 67 \quad 67 \quad 67 \quad 6968 \quad 66 \quad 21$

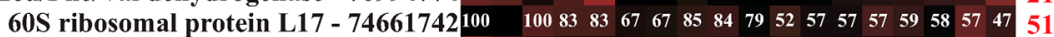

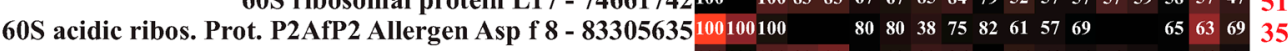

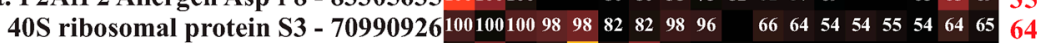

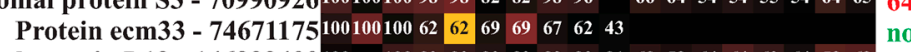

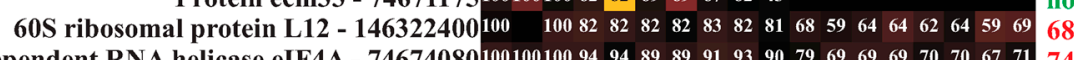
ATP-dependent RNA helicase eIF4A - 7467408010010010094 $94 \quad 89899193907969696970706771 \quad 74$

Figure 3. Quantities and homologies of proteins from fungal cell extracts. The color gradients in the heat map represent quantities of the closest detected homolog, and the numbers in each box give the degree of homology as percent sequence identity to the corresponding protein homolog in A. fumigatus. Black boxes that contain no numbers indicate absence of a detected homolog. 


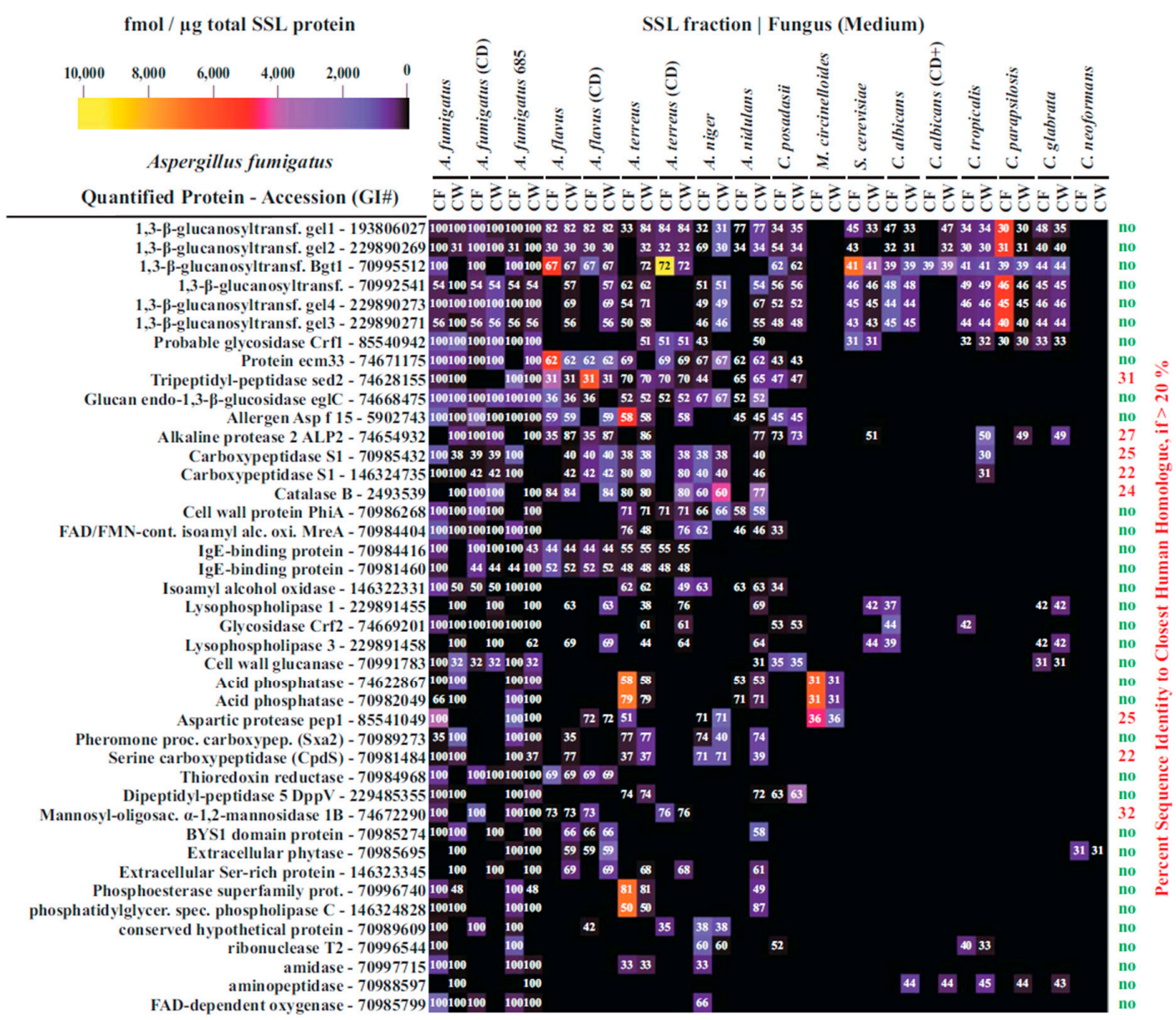

Figure 4. Quantities and homologies of fungal proteins with secreted or surface localization (SSL). The color gradients in the heat map represent quantities of the closest detected homolog in culture filtrate (CF) or cell wall (CW) extracts. The numbers in each box give the degree of homology as percent sequence identity to the corresponding protein homolog in A. fumigatus. Black boxes that contain no numbers indicate absence of a detected homolog.

Among the most abundantly expressed proteins only a few significant differences were discovered when comparing fungi cultured in rich versus minimal medium. CE fractions from fungi grown in the rich PD medium contained many more identified proteins than $\mathrm{CE}$ fractions from fungi grown in minimal CD medium (363-615 proteins for PD medium vs. 132-320 for CD medium). It appears that the detection threshold was substantially lower in PD fractions (0.5-3 versus 5-15 fmol per microgram total protein), possibly because fractions from $\mathrm{CD}$ grown cultures contained more highly abundant proteins, which may have masked less abundant peptides.

\subsection{Functional Annotation of A. fumigatus and C. albicans Proteins}

Functional annotation was performed manually for the 20 most abundant proteins in A. fumigatus and C. albicans fractions. For CF and CW fractions, only proteins with predicted SSL were considered, and only 15 SSL proteins were available for analysis in C. albicans CW fractions. In CE fractions, 11-15 proteins had known functions in glycolysis, respiration, translation, and as antioxidants (Figure 5A). C. albicans had more abundant proteins involved in glycolysis (6-7 of the 20 most abundant compared to 2-3 for A. fumigatus), while A. fumigatus had more abundant proteins devoted to translation (3-4 of the 20 most abundant compared to 1-2 for $C$. albicans). In CF fractions, 4-6 proteins of unknown function were detected, as were $2-6$ proteins involved in digestion, usually proteases or 
amylases (Figure 5B). Interestingly, 6-8 proteins involved in cell wall remodeling were also detected in all fractions. C. albicans fractions contained more cell-cell adhesion proteins, while A. fumigatus fractions contained more proteins of miscellaneous function, including antioxidants and metabolism-related proteins. These same patterns were retained in CW fractions (Figure 5C).
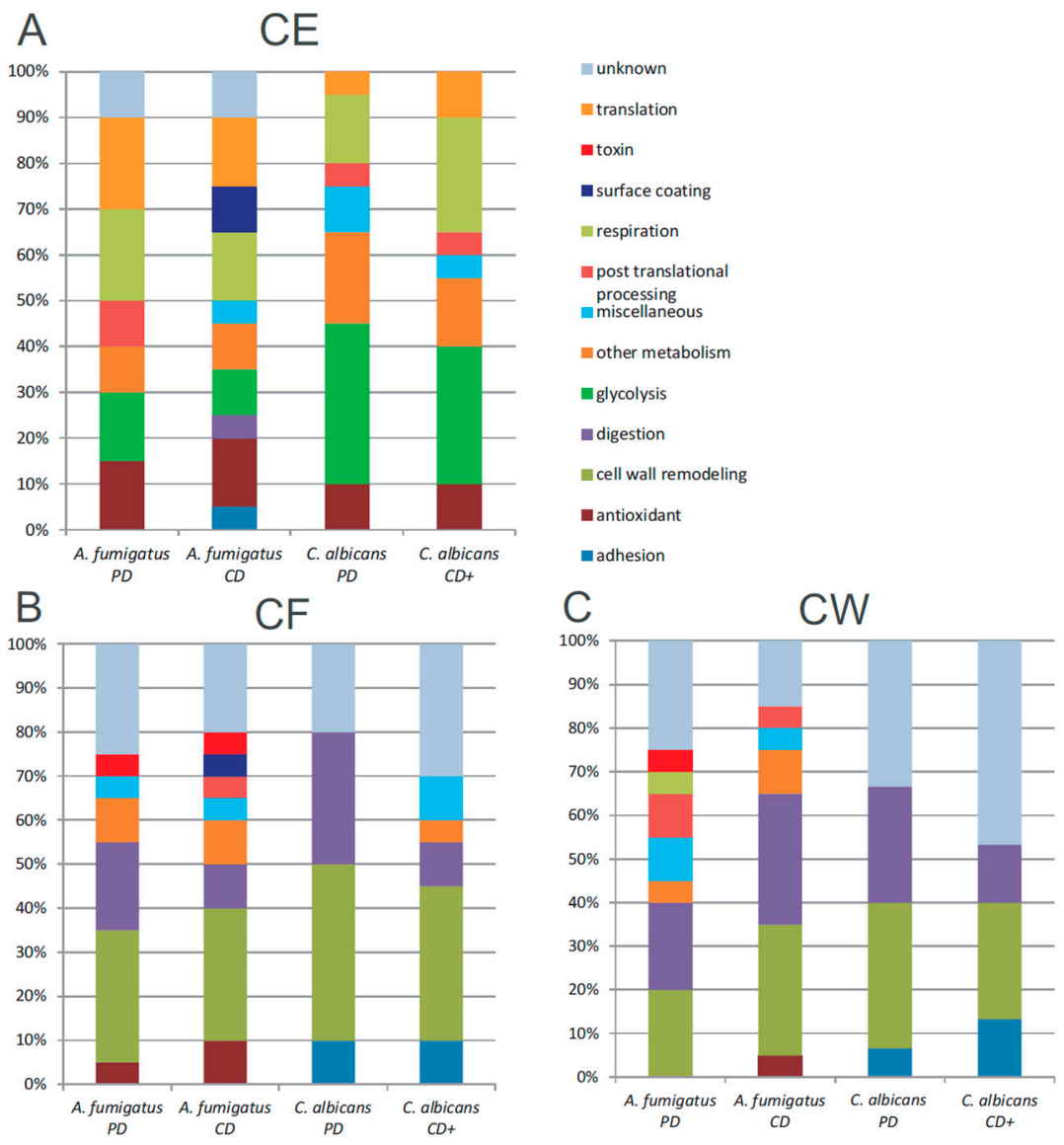

Figure 5. Functional annotation of the most abundant proteins in A. fumigatus and C. albicans. PD—Potato Dextrose Medium. CD—Czapek Dox Medium (+-with casamino acid supplementation).

(A) CE-Cell Extract Fraction (SSL proteins); (B) CF-Culture Filtrate Fraction (SSL proteins);

(C) CW-Cell Wall Fraction.

\section{Discussion}

It was the goal of our study to identify abundantly expressed fungi-typical proteins that share only little homology to human proteins. Such proteins should be interesting to future studies that are aimed to develop vaccine candidates or drug targets. To refine the localization of such proteins, we applied a fractionation strategy that focused on cytosolic, cell wall, and secreted proteins. As common with cellular fractionation methods, none provides perfect enrichment. We carefully conducted enzymatic cell wall digestion and used mass spectrometry to guard for the eventual release of cytosolic proteins, which would have indicated over digestion. Bioinformatic analysis indicated that an average of $71 \%$ of CF proteins, and $\sim 48 \%$ of CW proteins had predicted SSL (Table 1), supporting substantial enrichment. Naturally, CW and CF fractions also contained several proteins with predicted intracellular localization. Nevertheless, our fractionation method still produced acceptably low levels of cross contamination, and therefore each fraction represents a distinct proteome. Predicted intracellular proteins in $\mathrm{CW}$ and $\mathrm{CF}$ fractions may in fact be cell wall or secreted proteins with unknown export signals. In fact, formation of extracellular vesicles by fungi has been reported previously [50-52]. In addition, the detection of cytosolic proteins in $\mathrm{CW}$ and $\mathrm{CF}$ fractions can result from natural autolysis 
of cells, which may release intracellular proteins that adhere to extracellular cell surfaces. Thus, such proteins are likely to form a natural part of the cell surface and the secreted proteome of most fungi. Indeed, a previous study found several predicted intracellular proteins on the extracellular surface of Cryptococcus, which were then successfully tested as vaccine candidates [53]. Here, we limited our set of abundantly expressed extracellular or surface localized proteins based on predicted SSL signals. As discussed below, abundantly expressed SSL proteins are largely conserved between fungal species and most distant from any human homologs.

Functional annotation of the most abundant proteins in A. fumigatus and C. albicans CE fractions revealed similar functions for fungi grown in PD and CD media (Figure 5). In CE fractions, proteins with a variety of biochemical functions related to metabolism and protein synthesis were found, as expected. However, A. fumigatus appeared to have lower expression levels of proteins involved in glycolysis and higher expression of proteins involved in translation. This may be because yeast such as $C$. albicans may rely more on glycolysis for energy in non-limiting conditions, while filamentous fungi rely more on aerobic respiration, consistent with previous microarray studies [54]. In CF and CW fractions of $A$. fumigatus and $C$. albicans, many abundant proteins of unknown function were detected (Tables S1, S2, S13 and S14), which may be good targets for future functional investigations regarding the interaction of fungi with their environment. Interestingly, several proteins involved in cell wall remodeling were found not just in CW fractions, but in CF fractions as well. These proteins may have been shed during the course of cell wall remodeling, or perhaps also serve other roles in carbohydrate processing. Such proteins, such as Crf1 and EglC in A. fumigatus, may also serve to inhibit the growth of other fungi by degrading their cell walls. C. albicans CF and CW fractions contained adhesion proteins allowing for cell-cell interaction, and consistently were not found in A. fumigatus $\mathrm{CF}$ and $\mathrm{CW}$ fractions. A. fumigatus, on the other hand, contained several abundant protein types of varying function in the $\mathrm{CW}$ and $\mathrm{CF}$ fractions not found in C. albicans, including established virulence factors such as the serine protease Asp f15 and ribotoxin Asp f1 [55].

The cell wall of pathogenic fungi plays an important role in host-pathogen interaction. Other studies have increasingly focused on proteins from this cellular site [56], and our study provides a first look at the cell wall proteomes, as well as other fractions of several species (Table 4). The CW proteins identified from hyphae in our study have very little overlap with those of the conidial cell wall proteome of A. fumigatus identified in a different study [57]. Thus, it appears that the A. fumigatus cell wall proteome undergoes major changes between the conidia and hyphae stages of the fungal lifecycle, particularly when the fungi are grown in rich medium, which is consistent with previous reports [58]. The intracellular proteome of conidia is also different from that of hyphae, though to a lesser extent $[59,60]$. The proteins detected in our A. fumigatus $C E, C F$, and $C W$ fractions were very similar in expression levels to our previous study in both PD and CD medium [61]. Our cell wall proteomes had few proteins in common with earlier studies on C. albicans [62,63] and C. glabrata [64], most likely due to differences in PD medium and the more commonly used yeast extract peptone dextrose medium. For example the Ecm33 homologs, which were abundant in the filamentous fungi studied here, were not detected in the fractions from yeast.

Our CF protein identifications had a fair amount of overlap with previous secretome studies of A. fumigatus [65,66], A. terreus [67], A. niger [68], A. flavus [69,70], C. albicans [71,72], and S. cerevisiae [73]. Differences between our results and these studies are likely due to differences in culture conditions, growth media, and sample preparation methods. Our protein identifications from CE fractions were also broadly similar to previous studies covering A. fumigatus [59,74], A. flavus [75,76], A. nidulans [77], C. albicans [78-80], C. glabrata [81], C. posadasii [23], C. neoformans [53,82], and S. cerevisiae [83-86]. We also identified many of the immunogenic proteins found in a study on C. parapsilosis, including an ATP synthase, an enolase, GAPDH, and others [87]. 
Table 4. Recently Published Fungal Proteomic Studies *.

\begin{tabular}{cccc}
\hline Species & CE & CF & CW \\
\hline Aspergillus flavus & {$[75,76]$} & {$[69,70]$} & - \\
Aspergillus fumigatus & {$[58-61,74]$} & {$[61,65,66]$} & {$[57,61]$} \\
Aspergillus nidulans & {$[77]$} & - & - \\
Aspergillus niger & - & {$[68]$} & - \\
Aspergillus terreus & - & {$[67]$} & - \\
Candida albicans & {$[78-80]$} & {$[71,72]$} & {$[62,63]$} \\
Candida glabrata & {$[81]$} & - & {$[64]$} \\
Candida parapsilosis & {$[87]$} & - & - \\
Candida tropicalis & - & - & - \\
Coccidioides posadasii & {$[23,61]$} & - & - \\
Cryptococcus neoformans & {$[53,82]$} & - & - \\
Mucor circinelloides & - & - & - \\
Saccharomyces cerevisiae & {$[83-86]$} & - & {$[73]$} \\
\hline
\end{tabular}

* Fraction: CE-Cell Extract, CF-Culture Filtrate, CW-Cell Wall; All fungi and fractions mentioned in the table were analyzed in this present study. Hyphens mark the absence of other published studies.

In recent studies, we tested serum from mice infected with C. posadasii, C. albicans or Paracoccidioides brasiliensis on a 4800 element ordered protein array of Saccharomyces cerevisiae to profile cross-reactive antigen proteins [88]. These sera detected 60 to 130 proteins each, including five that we had reported in our initial studies using immunoblotting and MS [61]; 16 detected proteins were common to all. Interestingly, no cell wall or GPI-anchored proteins were detected using this method of screening, possibly due to low titers of antibody in the sera or stimulation of primarily a cell-mediated immune response. This difficulty is obviated by the MS methodology, which allows us to analyze all proteins present in a sample preparation or cellular fraction, even if they do not stimulate a strong antibody response.

Conserved fungal proteins could become components of vaccines that protect against multiple species of fungi. For example, crude complex vaccines such as heat-killed Saccharomyces cerevisiae has been protective in experiment models of aspergillosis [43], candidiasis [89], coccidioidomycosis [42], cryptococcosis [90], and mucormycosis [44]. It is striking that the aspergillosis vaccine candidate Asp f3 from A. fumigatus [16-19] shares 70\% sequence identity with the coccidioidomycosis vaccine candidate Pmp1 from C. posadasii [23]. Similarly, Pep2 from A. fumigatus [21] and Pep1 from C. posadasii [24] share $77 \%$ sequence identity, and Gel1 from A. fumigatus [21] and from C. posadasii [25] have 69\% identity. Furthermore, the A. fumigatus protein Crf1 protects not only against aspergillosis, but also candidiasis [22], despite exhibiting only $48 \%$ identity across $66 \%$ of the homologous C. albicans protein. An ideal vaccine candidate would be most effective if it were expressed throughout the growth cycle of fungi, particularly by conidia in filamentous fungi. Additionally, such a protein vaccine candidate would be localized to the cell wall, to allow for easier immune access, including by antibodies. Finally, when selecting proteins as potential vaccine candidates, it is desirable for the protein to be expressed at a high level by the fungus during infection in vivo. Using studies in vitro, the chance of this can be maximized by using proteins that are expressed in multiple growth conditions. Such expression would likely also be conserved in vivo, as supported by other published observations [61,88]. A superior vaccine may be created by selecting immunogenic epitopes of several proteins and combining them into a recombinant protein. In support of this strategy, a combination of recombinant Pep1, Alm1, and $\mathrm{Plb} 1$ in a vaccine formulation provided increased protection against Coccidioides infection compared to each individual protein alone [91]. Indeed, the flexibility of this strategy may allow for a single multivalent protein vaccine to be designed for protection against different species of fungi using epitopes of multiple proteins from several species. If such epitopes were linked by cathepsin cut sites, immune processing in the endolysosome may be enhanced, leading to a more efficient vaccine. Efficiency could be further increased by selecting individual epitopes that provide protection against multiple species of fungi. 


\section{Conclusions}

We have discovered several cell wall proteins with homology and expression across different species (Figure 4) that that may be suitable candidates for identification of these protective epitopes. Our best candidates with high expression in multiple species of fungi and no homology to human proteins are the 1,3- $\beta$-glucanosyltransferases, including Gel1-4, Bgt1, and their homologs. Other interesting candidates discovered are Crf1, Ecm33, and EglC. It is noteworthy that Crf1 and Gel1 have already been shown to be promising vaccine candidates, while the other proteins remain to be tested. Vaccine trials with our abundant homologous fungal candidate proteins (Figure 4) should be performed to assess protection against multiple species of fungi.

Acknowledgments: We thank Roger Moore at the City of Hope Mass Spectrometry Core Facility, Duarte, CA, USA for his assistance, and we thank Vicky Chen, Jason Yu, Miriam Champer, Mayyen Wong, Alexandra Wong, and Molly Shannahoff for their contributions. Facilities used in this study were supported in parts by National Cancer Institute of the National Institutes of Health under award number P30CA33572. Jackson Champer and Markus Kalkum were supported by the Hermann Foundation, and the Tim Nesvig Lymphoma Fellowship and Research Fund. Jackson Champer was supported in part by the Helen \& and Morgan Chu Fellowship at the Irell and Manella Graduate School of Biological Sciences, City of Hope, Duarte, CA, USA.

Author Contributions: Jackson Champer, Karl V. Clemons, David A. Stevens, and Markus Kalkum conceived and designed the experiments; Jackson Champer and Karl V. Clemons performed the experiments; James I. Ito provided clinical isolates of fungi and their initial identification by clinical microbiology; Jackson Champer and Markus Kalkum analyzed the data; all authors participated in writing of the paper.

Conflicts of Interest: The authors report no conflicts of interest. The authors alone are responsible for the content and the writing of the paper.

\section{References}

1. Singh, N.; Paterson, D.L. Aspergillus infections in transplant recipients. Clin. Microbiol. Rev. 2005, 18, 44-69. [CrossRef] [PubMed]

2. Caston-Osorio, J.J.; Rivero, A.; Torre-Cisneros, J. Epidemiology of invasive fungal infection. Int. J. Antimicrob. Agents 2008, 32, S103-S109. [CrossRef]

3. Kontoyiannis, D.P.; Marr, K.A.; Park, B.J.; Alexander, B.D.; Anaissie, E.J.; Walsh, T.J.; Ito, J.; Andes, D.R.; Baddley, J.W.; Brown, J.M.; et al. Prospective surveillance for invasive fungal infections in hematopoietic stem cell transplant recipients, 2001-2006: Overview of the Transplant-Associated Infection Surveillance Network (TRANSNET) Database. Clin. Infect. Dis. 2010, 50, 1091-1100. [CrossRef] [PubMed]

4. Shoham, S.; Marr, K.A. Invasive fungal infections in solid organ transplant recipients. Future Microbiol. 2012, 7, 639-655. [CrossRef] [PubMed]

5. Pagano, L.; Caira, M.; Candoni, A.; Offidani, M.; Fianchi, L.; Martino, B.; Pastore, D.; Picardi, M.; Bonini, A.; Chierichini, A.; et al. The epidemiology of fungal infections in patients with hematologic malignancies: The SEIFEM-2004 study. Haematologica 2006, 91, 1068-1075. [PubMed]

6. Dotis, J.; Iosifidis, E.; Roilides, E. Central nervous system aspergillosis in children: A systematic review of reported cases. Int. J. Infect. Dis. 2007, 11, 381-393. [CrossRef] [PubMed]

7. Schaal, J.V.; Leclerc, T.; Soler, C.; Donat, N.; Cirrode, A.; Jault, P.; Bargues, L. Epidemiology of filamentous fungal infections in burned patients: A French retrospective study. Burns 2015, 41, 853-863. [CrossRef] [PubMed]

8. Denning, D.W.; Follansbee, S.E.; Scolaro, M.; Norris, S.; Edelstein, H.; Stevens, D.A. Pulmonary aspergillosis in the acquired immunodeficiency syndrome. N. Engl. J. Med. 1991, 324, 654-662. [CrossRef] [PubMed]

9. Stevens, D.A.; Melikian, G.L. Aspergillosis in the "nonimmunocompromised" host. Immunol. Investig. 2011, 40, 751-766. [CrossRef] [PubMed]

10. Hector, R.F.; Laniado-Laborin, R. Coccidioidomycosis-A fungal disease of the Americas. PLoS Med. 2005, 2, e2. [CrossRef] [PubMed]

11. Dagenais, T.R.; Keller, N.P. Pathogenesis of Aspergillus fumigatus in invasive aspergillosis. Clin. Microbiol. Rev. 2009, 22, 447-465. [CrossRef] [PubMed]

12. Verweij, P.E.; Howard, S.J.; Melchers, W.J.; Denning, D.W. Azole-resistance in Aspergillus: Proposed nomenclature and breakpoints. Drug Resist. Updat. 2009, 12, 141-147. [CrossRef] [PubMed] 
13. Chen, S.C.; Playford, E.G.; Sorrell, T.C. Antifungal therapy in invasive fungal infections. Curr. Opin. Pharmacol. 2010, 10, 522-530. [CrossRef] [PubMed]

14. Ahmad, S.; Joseph, L.; Hagen, F.; Meis, J.F.; Khan, Z. Concomitant occurrence of itraconazole-resistant and -susceptible strains of Aspergillus fumigatus in routine cultures. J. Antimicrob. Chemother. 2015, 70, 412-415. [CrossRef] [PubMed]

15. Steinmann, J.; Hamprecht, A.; Vehreschild, M.J.; Cornely, O.A.; Buchheidt, D.; Spiess, B.; Koldehoff, M.; Buer, J.; Meis, J.F.; Rath, P.M. Emergence of azole-resistant invasive aspergillosis in HSCT recipients in Germany. J. Antimicrob. Chemother. 2015, 70, 1522-1526. [CrossRef] [PubMed]

16. Ito, J.I.; Lyons, J.M.; Diaz-Arevalo, D.; Hong, T.B.; Kalkum, M. Vaccine progress. Med. Mycol. 2009, 47, S394-S400. [CrossRef] [PubMed]

17. Diaz-Arevalo, D.; Bagramyan, K.; Hong, T.B.; Ito, J.I.; Kalkum, M. CD4+ T Cells mediate the protective effect of the recombinant Asp f3-based anti-aspergillosis vaccine. Infect. Immun. 2011, 79, 2257-2266. [CrossRef] [PubMed]

18. Diaz-Arevalo, D.; Ito, J.I.; Kalkum, M. Protective effector cells of the recombinant Asp f3 anti-aspergillosis vaccine. Front. Microbiol. 2012, 3. [CrossRef] [PubMed]

19. Ito, J.I.; Lyons, J.M.; Hong, T.B.; Tamae, D.; Liu, Y.K.; Wilczynski, S.P.; Kalkum, M. Vaccinations with recombinant variants of Aspergillus fumigatus Asp $\mathrm{f} 3$ protect against invasive aspergillosis. Infect. Immun. 2006, 74, 5075-5084. [CrossRef] [PubMed]

20. Bozza, S.; Gaziano, R.; Lipford, G.B.; Montagnoli, C.; Bacci, A.; di Francesco, P.; Kurup, V.P.; Wagner, H.; Romani, L. Vaccination of mice against invasive aspergillosis with recombinant Aspergillus proteins and CpG oligodeoxynucleotides as adjuvants. Microbes Infect. 2002, 4, 1281-1290. [CrossRef]

21. Bozza, S.; Clavaud, C.; Giovannini, G.; Fontaine, T.; Beauvais, A.; Sarfati, J.; D’Angelo, C.; Perruccio, K.; Bonifazi, P.; Zagarella, S.; et al. Immune sensing of Aspergillus fumigatus proteins, glycolipids, and polysaccharides and the impact on Th immunity and vaccination. J. Immunol. 2009, 183, 2407-2414. [CrossRef] [PubMed]

22. Stuehler, C.; Khanna, N.; Bozza, S.; Zelante, T.; Moretti, S.; Kruhm, M.; Lurati, S.; Conrad, B.; Worschech, E.; Stevanovic, S.; et al. Cross-protective TH1 immunity against Aspergillus fumigatus and Candida albicans. Blood 2011, 117, 5881-5891. [CrossRef] [PubMed]

23. Orsborn, K.I.; Shubitz, L.F.; Peng, T.; Kellner, E.M.; Orbach, M.J.; Haynes, P.A.; Galgiani, J.N. Protein expression profiling of Coccidioides posadasii by two-dimensional differential in-gel electrophoresis and evaluation of a newly recognized peroxisomal matrix protein as a recombinant vaccine candidate. Infect. Immun. 2006, 74, 1865-1872. [CrossRef] [PubMed]

24. Tarcha, E.J.; Basrur, V.; Hung, C.Y.; Gardner, M.J.; Cole, G.T. A recombinant aspartyl protease of Coccidioides posadasii induces protection against pulmonary coccidioidomycosis in mice. Infect. Immun. 2006, 74, 516-527. [CrossRef] [PubMed]

25. Delgado, N.; Xue, J.; Yu, J.J.; Hung, C.Y.; Cole, G.T. A recombinant $\beta$-1,3-glucanosyltransferase homolog of Coccidioides posadasii protects mice against coccidioidomycosis. Infect. Immun. 2003, 71, 3010-3019. [CrossRef] [PubMed]

26. Shibasaki, S.; Aoki, W.; Nomura, T.; Karasaki, M.; Sewaki, T.; Ueda, M. Evaluation of Mdh1 protein as an antigenic candidate for a vaccine against candidiasis. Biocontrol. Sci. 2014, 19, 51-55. [CrossRef] [PubMed]

27. Vilanova, M.; Teixeira, L.; Caramalho, I.; Torrado, E.; Marques, A.; Madureira, P.; Ribeiro, A.; Ferreira, P.; Gama, M.; Demengeot, J. Protection against systemic candidiasis in mice immunized with secreted aspartic proteinase 2. Immunology 2004, 111, 334-342. [CrossRef] [PubMed]

28. Spellberg, B.; Ibrahim, A.S.; Yeaman, M.R.; Lin, L.; Fu, Y.; Avanesian, V.; Bayer, A.S.; Filler, S.G.; Lipke, P.; Otoo, H.; et al. The antifungal vaccine derived from the recombinant $\mathrm{N}$ terminus of Als3p protects mice against the bacterium Staphylococcus aureus. Infect. Immun. 2008, 76, 4574-4580. [CrossRef] [PubMed]

29. Spellberg, B.J.; Ibrahim, A.S.; Avanesian, V.; Fu, Y.; Myers, C.; Phan, Q.T.; Filler, S.G.; Yeaman, M.R.; Edwards, J.E., Jr. Efficacy of the anti-Candida rAls3p-N or rAls1p-N vaccines against disseminated and mucosal candidiasis. J. Infect. Dis. 2006, 194, 256-260. [CrossRef] [PubMed]

30. Ibrahim, A.S.; Luo, G.; Gebremariam, T.; Lee, H.; Schmidt, C.S.; Hennessey, J.P., Jr.; French, S.W.; Yeaman, M.R.; Filler, S.G.; Edwards, J.E., Jr. NDV-3 protects mice from vulvovaginal candidiasis through T- and B-cell immune response. Vaccine 2013, 31, 5549-5556. [CrossRef] [PubMed] 
31. Schmidt, C.S.; White, C.J.; Ibrahim, A.S.; Filler, S.G.; Fu, Y.; Yeaman, M.R.; Edwards, J.E., Jr.; Hennessey, J.P., Jr. NDV-3, a recombinant alum-adjuvanted vaccine for Candida and Staphylococcus aureus, is safe and immunogenic in healthy adults. Vaccine 2012, 30, 7594-7600. [CrossRef] [PubMed]

32. Cassone, A. Development of vaccines for Candida albicans: Fighting a skilled transformer. Nat. Rev. Microbiol. 2013, 11, 884-891. [CrossRef] [PubMed]

33. Stevens, D.A.; Clemons, K.V.; Liu, M. Developing a vaccine against aspergillosis. Med. Mycol. 2011, 49, S170-S176. [CrossRef] [PubMed]

34. Cassone, A.; Rappuoli, R. Universal vaccines: Shifting to one for many. MBio 2010, 1. [CrossRef] [PubMed]

35. Cheng, F.Y.; Blackburn, K.; Lin, Y.M.; Goshe, M.B.; Williamson, J.D. Absolute protein quantification by $\mathrm{LC} / \mathrm{MS}^{\mathrm{E}}$ for global analysis of salicylic acid-induced plant protein secretion responses. J. Proteome Res. 2009, 8, 82-93. [CrossRef] [PubMed]

36. Bostanci, N.; Heywood, W.; Mills, K.; Parkar, M.; Nibali, L.; Donos, N. Application of label-free absolute quantitative proteomics in human gingival crevicular fluid by $\mathrm{LC} / \mathrm{MS}^{\mathrm{E}}$ (gingival exudatome). J. Proteome Res. 2010, 9, 2191-2199. [CrossRef] [PubMed]

37. Li, G.Z.; Vissers, J.P.; Silva, J.C.; Golick, D.; Gorenstein, M.V.; Geromanos, S.J. Database searching and accounting of multiplexed precursor and product ion spectra from the data independent analysis of simple and complex peptide mixtures. Proteomics 2009, 9, 1696-1719. [CrossRef] [PubMed]

38. Geromanos, S.J.; Vissers, J.P.; Silva, J.C.; Dorschel, C.A.; Li, G.Z.; Gorenstein, M.V.; Bateman, R.H.; Langridge, J.I. The detection, correlation, and comparison of peptide precursor and product ions from data independent LC-MS with data dependant LC-MS/MS. Proteomics 2009, 9, 1683-1695. [CrossRef] [PubMed]

39. Vissers, J.P.; Pons, S.; Hulin, A.; Tissier, R.; Berdeaux, A.; Connolly, J.B.; Langridge, J.I.; Geromanos, S.J.; Ghaleh, B. The use of proteome similarity for the qualitative and quantitative profiling of reperfused myocardium. J. Chromatogr. B Anal. Technol. Biomed. Life Sci. 2009, 877, 1317-1326. [CrossRef] [PubMed]

40. Ito, J.I.; Lyons, J.M. Vaccination of corticosteroid immunosuppressed mice against invasive pulmonary aspergillosis. J. Infect. Dis. 2002, 186, 869-871. [CrossRef] [PubMed]

41. Levine, H.B.; Stevens, D.A.; Cobb, J.M.; Gebhardt, A.E. Miconazole in coccidioidomycosis. I. Assays of activity in mice and in vitro. J. Infect. Dis. 1975, 132, 407-414. [CrossRef] [PubMed]

42. Capilla, J.; Clemons, K.V.; Liu, M.; Levine, H.B.; Stevens, D.A. Saccharomyces cerevisiae as a vaccine against coccidioidomycosis. Vaccine 2009, 27, 3662-3668. [CrossRef] [PubMed]

43. Liu, M.; Capilla, J.; Johansen, M.E.; Alvarado, D.; Martinez, M.; Chen, V.; Clemons, K.V.; Stevens, D.A. Saccharomyces as a vaccine against systemic aspergillosis: "The friend of man" a friend again? J. Med. Microbiol. 2011, 60, 1423-1432. [CrossRef] [PubMed]

44. Luo, G.; Gebremariam, T.; Clemons, K.V.; Stevens, D.A.; Ibrahim, A.S. Heat-killed yeast protects diabetic ketoacidotic-steroid treated mice from pulmonary mucormycosis. Vaccine 2014, 32, 3573-3576. [CrossRef] [PubMed]

45. Enache-Angoulvant, A.; Hennequin, C. Invasive Saccharomyces infection: A comprehensive review. Clin. Infect. Dis. 2005, 41, 1559-1568. [CrossRef] [PubMed]

46. Hong, T.B.; Kalkum, M. Using A Ball Mill for Cryogenic Disruption of Yeast Cells. Available online: http:/ / www.biosciencetechnology.com/articles/2004/01/using-ball-mill-cryogenic-disruption-yeast-cells (accessed on 6 January 2016).

47. Singer, M.A.; Lindquist, S. Multiple effects of trehalose on protein folding in vitro and in vivo. Mol. Cell 1998, 1, 639-648. [CrossRef]

48. Horton, P.; Park, K.J.; Obayashi, T.; Fujita, N.; Harada, H.; Adams-Collier, C.J.; Nakai, K. Wolf Psort: Protein localization predictor. Nucleic Acids Res. 2007, 35, W585-W587. [CrossRef] [PubMed]

49. Altschul, S.F.; Gish, W.; Miller, W.; Myers, E.W.; Lipman, D.J. Basic local alignment search tool. J. Mol. Biol. 1990, 215, 403-410. [CrossRef]

50. Vallejo, M.C.; Nakayasu, E.S.; Matsuo, A.L.; Sobreira, T.J.; Longo, L.V.; Ganiko, L.; Almeida, I.C.; Puccia, R. Vesicle and vesicle-free extracellular proteome of Paracoccidioides brasiliensis: Comparative analysis with other pathogenic fungi. J. Proteome Res. 2012, 11, 1676-1685. [CrossRef] [PubMed] 
51. Oliveira, D.L.; Nakayasu, E.S.; Joffe, L.S.; Guimaraes, A.J.; Sobreira, T.J.; Nosanchuk, J.D.; Cordero, R.J.; Frases, S.; Casadevall, A.; Almeida, I.C.; et al. Characterization of yeast extracellular vesicles: Evidence for the participation of different pathways of cellular traffic in vesicle biogenesis. PLOS ONE 2010, 5, e11113. [CrossRef] [PubMed]

52. Peres da Silva, R.; Puccia, R.; Rodrigues, M.L.; Oliveira, D.L.; Joffe, L.S.; Cesar, G.V.; Nimrichter, L.; Goldenberg, S.; Alves, L.R. Extracellular vesicle-mediated export of fungal RNA. Sci. Rep. 2015, 5, 7763. [CrossRef] [PubMed]

53. Chaturvedi, A.K.; Weintraub, S.T.; Lopez-Ribot, J.L.; Wormley, F.L., Jr. Identification and characterization of Cryptococcus neoformans protein fractions that induce protective immune responses. Proteomics 2013, 13, 3429-3441. [CrossRef] [PubMed]

54. Breakspear, A.; Momany, M. The first fifty microarray studies in filamentous fungi. Microbiology 2007, 153, 7-15. [CrossRef] [PubMed]

55. Abad, A.; Fernandez-Molina, J.V.; Bikandi, J.; Ramirez, A.; Margareto, J.; Sendino, J.; Hernando, F.L.; Ponton, J.; Garaizar, J.; Rementeria, A. What makes Aspergillus fumigatus a successful pathogen? Genes and molecules involved in invasive aspergillosis. Rev. Iberoam. Micol. 2010, 27, 155-182. [CrossRef] [PubMed]

56. Karkowska-Kuleta, J.; Kozik, A. Cell wall proteome of pathogenic fungi. Acta Biochim. Pol. 2015, 62, $339-351$. [CrossRef] [PubMed]

57. Asif, A.R.; Oellerich, M.; Amstrong, V.W.; Riemenschneider, B.; Monod, M.; Reichard, U. Proteome of conidial surface associated proteins of Aspergillus fumigatus reflecting potential vaccine candidates and allergens. J. Proteome Res. 2006, 5, 954-962. [CrossRef] [PubMed]

58. Cagas, S.E.; Jain, M.R.; Li, H.; Perlin, D.S. The proteomic signature of Aspergillus fumigatus during early development. Mol. Cell. Proteom. 2011, 10. [CrossRef] [PubMed]

59. Teutschbein, J.; Albrecht, D.; Potsch, M.; Guthke, R.; Aimanianda, V.; Clavaud, C.; Latge, J.P.; Brakhage, A.A.; Kniemeyer, O. Proteome profiling and functional classification of intracellular proteins from conidia of the human-pathogenic mold Aspergillus fumigatus. J. Proteome Res. 2010, 9, 3427-3442. [CrossRef] [PubMed]

60. Suh, M.J.; Fedorova, N.D.; Cagas, S.E.; Hastings, S.; Fleischmann, R.D.; Peterson, S.N.; Perlin, D.S.; Nierman, W.C.; Pieper, R.; Momany, M. Development stage-specific proteomic profiling uncovers small, lineage specific proteins most abundant in the Aspergillus fumigatus conidial proteome. Proteome Sci. 2012, 10, 30. [CrossRef] [PubMed]

61. Champer, J.; Diaz-Arevalo, D.; Champer, M.; Hong, T.B.; Wong, M.; Shannahoff, M.; Ito, J.I.; Clemons, K.V.; Stevens, D.A.; Kalkum, M. Protein targets for broad-spectrum mycosis vaccines: Quantitative proteomic analysis of Aspergillus and Coccidioides and comparisons with other fungal pathogens. Ann. N. Y. Acad. Sci. 2012, 1273, 44-51. [CrossRef] [PubMed]

62. Heilmann, C.J.; Sorgo, A.G.; Mohammadi, S.; Sosinska, G.J.; de Koster, C.G.; Brul, S.; de Koning, L.J.; Klis, F.M. Surface stress induces a conserved cell wall stress response in the pathogenic fungus Candida albicans. Eukaryot. Cell 2013, 12, 254-264. [CrossRef] [PubMed]

63. Heilmann, C.J.; Sorgo, A.G.; Siliakus, A.R.; Dekker, H.L.; Brul, S.; de Koster, C.G.; de Koning, L.J.; Klis, F.M. Hyphal induction in the human fungal pathogen Candida albicans reveals a characteristic wall protein profile. Microbiology 2011, 157, 2297-2307. [CrossRef] [PubMed]

64. Gomez-Molero, E.; de Boer, A.D.; Dekker, H.L.; Moreno-Martinez, A.; Kraneveld, E.A.; Chauhan, I.N.; Weig, M.; de Soet, J.J.; de Koster, C.G.; et al. Proteomic analysis of hyperadhesive Candida glabrata clinical isolates reveals a core wall proteome and differential incorporation of adhesins. FEMS Yeast Res. 2015, 15. [CrossRef]

65. Singh, B.; Oellerich, M.; Kumar, R.; Kumar, M.; Bhadoria, D.P.; Reichard, U.; Gupta, V.K.; Sharma, G.L.; Asif, A.R. Immuno-reactive molecules identified from the secreted proteome of Aspergillus fumigatus. J. Proteome Res. 2010, 9, 5517-5529. [CrossRef] [PubMed]

66. Kumar, A.; Ahmed, R.; Singh, P.K.; Shukla, P.K. Identification of virulence factors and diagnostic markers using immunosecretome of Aspergillus fumigatus. J. Proteom. 2011, 74, 1104-1112. [CrossRef] [PubMed]

67. Han, M.J.; Kim, N.J.; Lee, S.Y.; Chang, H.N. Extracellular proteome of Aspergillus terreus grown on different carbon sources. Curr. Genet. 2010, 56, 369-382. [CrossRef] [PubMed]

68. Krijgsheld, P.; Altelaar, A.F.; Post, H.; Ringrose, J.H.; Muller, W.H.; Heck, A.J.; Wosten, H.A. Spatially resolving the secretome within the mycelium of the cell factory Aspergillus niger. J. Proteome Res. 2012, 11, 2807-2818. [CrossRef] [PubMed] 
69. Medina, M.L.; Haynes, P.A.; Breci, L.; Francisco, W.A. Analysis of secreted proteins from Aspergillus flavus. Proteomics 2005, 5, 3153-3161. [CrossRef] [PubMed]

70. Selvam, R.M.; Nithya, R.; Devi, P.N.; Shree, R.S.; Nila, M.V.; Demonte, N.L.; Thangavel, C.; Maheshwari, J.J.; Lalitha, P.; Prajna, N.V.; et al. Exoproteome of Aspergillus flavus corneal isolates and saprophytes: Identification of proteoforms of an oversecreted alkaline protease. J. Proteom. 2015, 115, 23-35. [CrossRef] [PubMed]

71. Gil-Bona, A.; Monteoliva, L.; Gil, C. Global proteomic profiling of the secretome of Candida albicans Ecm33 cell wall mutant reveals the involvement of Ecm33 in Sap2 secretion. J. Proteome Res. 2015, 14, 4270-4281. [CrossRef] [PubMed]

72. Klis, F.M.; Brul, S. Adaptations of the secretome of Candida albicans in response to host-related environmental conditions. Eukaryot. Cell 2015, 14, 1165-1172. [CrossRef] [PubMed]

73. Giardina, B.J.; Stanley, B.A.; Chiang, H.L. Glucose induces rapid changes in the secretome of Saccharomyces cerevisiae. Proteome Sci. 2014, 12, 9. [CrossRef] [PubMed]

74. Vodisch, M.; Albrecht, D.; Lessing, F.; Schmidt, A.D.; Winkler, R.; Guthke, R.; Brakhage, A.A.; Kniemeyer, O. Two-dimensional proteome reference maps for the human pathogenic filamentous fungus Aspergillus fumigatus. Proteomics 2009, 9, 1407-1415. [CrossRef] [PubMed]

75. Pechanova, O.; Pechan, T.; Rodriguez, J.M.; Williams, W.P.; Brown, A.E. A two-dimensional proteome map of the aflatoxigenic fungus Aspergillus flavus. Proteomics 2013, 13, 1513-1518. [CrossRef] [PubMed]

76. Zhang, F.; Zhong, H.; Han, X.; Guo, Z.; Yang, W.; Liu, Y.; Yang, K.; Zhuang, Z.; Wang, S. Proteomic profile of Aspergillus flavus in response to water activity. Fungal Biol. 2015, 119, 114-124. [CrossRef] [PubMed]

77. Wartenberg, D.; Vodisch, M.; Kniemeyer, O.; Albrecht-Eckardt, D.; Scherlach, K.; Winkler, R.; Weide, M.; Brakhage, A.A. Proteome analysis of the farnesol-induced stress response in Aspergillus nidulans-The role of a putative dehydrin. J. Proteom. 2012, 75, 4038-4049. [CrossRef] [PubMed]

78. Aoki, W.; Ueda, T.; Tatsukami, Y.; Kitahara, N.; Morisaka, H.; Kuroda, K.; Ueda, M. Time-course proteomic profile of Candida albicans during adaptation to a fetal serum. Pathog. Dis. 2013, 67, 67-75. [CrossRef] [PubMed]

79. Vialas, V.; Sun, Z.; Loureiro, Y.P.C.V.; Carrascal, M.; Abian, J.; Monteoliva, L.; Deutsch, E.W.; Aebersold, R.; Moritz, R.L.; Gil, C. A Candida albicans PeptideAtlas. J. Proteom. 2014, 97, 62-68. [CrossRef] [PubMed]

80. Vialas, V.; Sun, Z.; Reales-Calderon, J.A.; Hernaez, M.L.; Casas, V.; Carrascal, M.; Abian, J.; Monteoliva, L.; Deutsch, E.W.; Moritz, R.L.; et al. A comprehensive Candida albicans PeptideAtlas build enables deep proteome coverage. J. Proteom. 2016, 131, 122-130. [CrossRef] [PubMed]

81. Prasad, T.S.; Harsha, H.C.; Keerthikumar, S.; Sekhar, N.R.; Selvan, L.D.; Kumar, P.; Pinto, S.M.; Muthusamy, B.; Subbannayya, Y.; Renuse, S.; et al. Proteogenomic analysis of Candida glabrata using high resolution mass spectrometry. J. Proteome Res. 2012, 11, 247-260. [CrossRef] [PubMed]

82. Santi, L.; Beys-da-Silva, W.O.; Berger, M.; Calzolari, D.; Guimaraes, J.A.; Moresco, J.J.; Yates, J.R., III. Proteomic profile of Cryptococcus neoformans biofilm reveals changes in metabolic processes. J. Proteome Res. 2014, 13, 1545-1559. [CrossRef] [PubMed]

83. Nagaraj, N.; Kulak, N.A.; Cox, J.; Neuhauser, N.; Mayr, K.; Hoerning, O.; Vorm, O.; Mann, M. System-wide perturbation analysis with nearly complete coverage of the yeast proteome by single-shot ultra HPLC runs on a bench top Orbitrap. Mol. Cell Proteom. 2012, 11. [CrossRef] [PubMed]

84. Richards, A.L.; Hebert, A.S.; Ulbrich, A.; Bailey, D.J.; Coughlin, E.E.; Westphall, M.S.; Coon, J.J. One-hour proteome analysis in yeast. Nat. Protoc. 2015, 10, 701-714. [CrossRef] [PubMed]

85. Selevsek, N.; Chang, C.Y.; Gillet, L.C.; Navarro, P.; Bernhardt, O.M.; Reiter, L.; Cheng, L.Y.; Vitek, O.; Aebersold, R. Reproducible and consistent quantification of the Saccharomyces cerevisiae proteome by SWATH-mass spectrometry. Mol. Cell Proteom. 2015, 14, 739-749. [CrossRef] [PubMed]

86. Vonk, R.J.; Gargano, A.F.; Davydova, E.; Dekker, H.L.; Eeltink, S.; de Koning, L.J.; Schoenmakers, P.J. Comprehensive Two-Dimensional Liquid Chromatography with Stationary-Phase-Assisted Modulation Coupled to High-Resolution Mass Spectrometry Applied to Proteome Analysis of Saccharomyces cerevisiae. Anal. Chem. 2015, 87, 5387-5394. [CrossRef] [PubMed]

87. Lee, P.Y.; Gam, L.H.; Yong, V.C.; Rosli, R.; Ng, K.P.; Chong, P.P. Identification of immunogenic proteins of Candida parapsilosis by serological proteome analysis. J. Appl. Microbiol. 2014, 116, 999-1009. [CrossRef] [PubMed] 
88. Coelho, P.S.; Im, H.; Clemons, K.V.; Snyder, M.P.; Stevens, D.A. Evaluating common humoral responses against fungal infections with yeast protein microarrays. J. Proteome Res. 2015, 14, 3924-3931. [CrossRef] [PubMed]

89. Liu, M.; Clemons, K.V.; Johansen, M.E.; Martinez, M.; Chen, V.; Stevens, D.A. Saccharomyces as a vaccine against systemic candidiasis. Immunol. Investig. 2012, 41, 847-855. [CrossRef] [PubMed]

90. Majumder, T.; Liu, M.; Chen, V.; Martinez, M.; Alvarado, D.; Clemons, K.V.; Stevens, D.A. Killed Saccharomyces cerevisiae protects against lethal challenge of Cryptococcus grubii. Mycopathologia 2014, 178, 189-195. [CrossRef] [PubMed]

91. Tarcha, E.J.; Basrur, V.; Hung, C.Y.; Gardner, M.J.; Cole, G.T. Multivalent recombinant protein vaccine against coccidioidomycosis. Infect. Immun. 2006, 74, 5802-5813. [CrossRef] [PubMed]

(C) 2016 by the authors; licensee MDPI, Basel, Switzerland. This article is an open access article distributed under the terms and conditions of the Creative Commons by Attribution (CC-BY) license (http://creativecommons.org/licenses/by/4.0/). 